\title{
Pollen grains adhere to the moist mouthparts in the flower visiting beetle Cetonia aurata (Scarabaeidae, Coleoptera)
}

\author{
Florian Karolyi · Stanislav N. Gorb · \\ Harald W. Krenn
}

Received: 4 June 2008/ Accepted: 28 November 2008/Published online: 17 December 2008

(C) Springer Science+Business Media B.V. 2008

\begin{abstract}
Flower visiting beetles possess numerous structural adaptations of their mouthparts to adhere and ingest pollen grains. Using a Cryo-SEM approach the examination of the mouthparts in rapidly frozen Cetonia aurata (Scarabaeidae) indicates a previously unknown technique of pollen uptake in Coleoptera. Cryo-SEM micrographs of the mouthparts reveal a fluid covering the bristles on the buccal surface. In this way the bristles of the galeae form a wet brush which represents the primary organ of pollen uptake. The fluid improves adhesion of pollen to bristles lacking any specialized adhering surface or highly sculptured cuticle as present in other pollen feeding Coleoptera. The well developed mola region of the otherwise non-biting mandibles of $C$. aurata indicates that these beetles open pollen grains mechanically before ingestion. Examination of gut content demonstrated that crushed and intact pollen occur in all regions. The CryoSEM method represents a new approach to study functional morphology including the interaction of microstructures and fluids on cuticular surfaces of insects.
\end{abstract}

Handling editor: Gimme Walter

F. Karolyi $(\bowtie) \cdot$ H. W. Krenn

Department of Evolutionary Biology, University of Vienna,

Althanstrasse 14, 1090 Vienna, Austria

e-mail: flokarolyi@hotmail.com

H. W. Krenn

e-mail: harald.krenn@univie.ac.at

\section{S. N. Gorb}

Evolutionary Biomaterials Group, Department of Thin Films of Biological Systems, Max-Planck-Institut für Metallforschung, Heisenbergstr. 3, 70569 Stuttgart, Germany

e-mail: s.gorb@mf.mpg.de
Keywords Mouthparts - Functional morphology · Pollen feeding · Cetonia aurata . Coleoptera . Flower visiting

\section{Introduction}

Many flower visiting insects consume pollen and therefore possess characteristic mouthpart adaptations for taking up pollen grains from flowers. Insect mouthparts are highly integrated structural units, forming interfaces with the environment (Betz et al. 2003). They often possess dense bristles for harvesting small pollen grains, as well as structural modifications for the manipulation of ingested pollen. Pollen feeding has been recorded for a number of species from various families of beetles. Their prognathous mouthparts are adequate for feeding on nectar, pollen and flower petals (Krenn et al. 2005).

Pollen grains are encased by a hard and highly resistant outer hull, the exine (Johnson and Nicolson 2000) and single grains range from 10 to $200 \mu \mathrm{m}$ in diameter (Stanley and Linskens 1974). The challenges confronting pollen feeders are the removal of the often dry pollen and gaining access to the encapsulated nutrition. Pollen is potentially a valuable food source for flower visiting insects since it contains a wide variety of lipids, carbohydrates and different protein concentrations (Johnson and Nicolson 2000).

Characteristic features of pollen feeding Coleoptera include an elongated maxillae with variously shaped combs and bristles that function as the primary pollen harvesting devices (Fuchs 1974). The mandibles, too, are particularly adapted for pollen manipulation and consist largely of the prostheca, a soft and usually bristly lobe, and the postmola which together knead the pollen (Schremmer 1961; Fuchs 1974; Nel and Scholtz 1990). The pollen grains are conveyed 
into the actual mouth opening by coordinated movements of the mouthparts (Fuchs 1974).

Although few investigations have been devoted to the mouthparts of flower visiting beetles, the functional anatomy of the mouthparts of the flower visiting rose beetle Cetonia aurata (Scarabaeidae) was previously studied in detail (Bürgis 1986a, b, 1987; Schremmer 1961). These studies concluded that the incisive part of the mandibles has lost its biting function, the mola part is responsible for crushing pollen and that the maxillae extend outward from their resting position under the clypeus and labrum with a semi-circular movement. Furthermore, the distal parts of the maxillae, i.e. the galeae, open laterally and extend forward. They reach into flowers and with their dense and wavy bristles sweep pollen grains into the cibarium (preoral cavity) during the retreating motion of the maxillae. Simultaneously, the laciniae with their short bristles convey any previously acquired pollen between the mandibles (Bürgis 1986a, b, 1987) (Fig. 1).

Despite the above mentioned studies on this frequently encountered European rose beetle, the full feeding mechanisms are not entirely understood. One open question concerns the possible interaction between pollen grains and the variously shaped bristles of the cuticle. The aim of this study was to examine the mouthparts of $C$. aurata under near natural conditions using a Cryo-scanning electron microscope. By examining rapidly frozen specimens which have not come in contact with liquids during preparation, this method allows the detection of pollen grains on mouthpart structures in their natural position. Any liquids naturally occurring on mouthpart surfaces will remain intact. The present examination represents the first application of this method for the visualisation of insect mouthparts. It demonstrated the presence of a liquid on the buccal surfaces of the mouthparts which compels us to new functional interpretations of mouthpart morphology and ultimately a deeper understanding of the pollen feeding mechanisms in this species. In addition, examination of the gut content should also provide insights in the role of different cuticular surfaces during feeding.

\section{Material and methods}

\section{Cryo-scanning electron microscope (Cryo-SEM)}

Specimens of the beetle Cetonia aurata (Coleoptera: Scarabaeidae, Cetoniinae), were collected from natural food plants in surroundings of Stuttgart-Vaihingen (southern Germany) and anaesthetized with $\mathrm{CO}_{2}$ prior to preparation.

Heads were severed from the body of anaesthetized insects with the use of sharp razor blades, glued with TissueTek O.C.T. fluid to brass stubs, and frozen in melting liquid

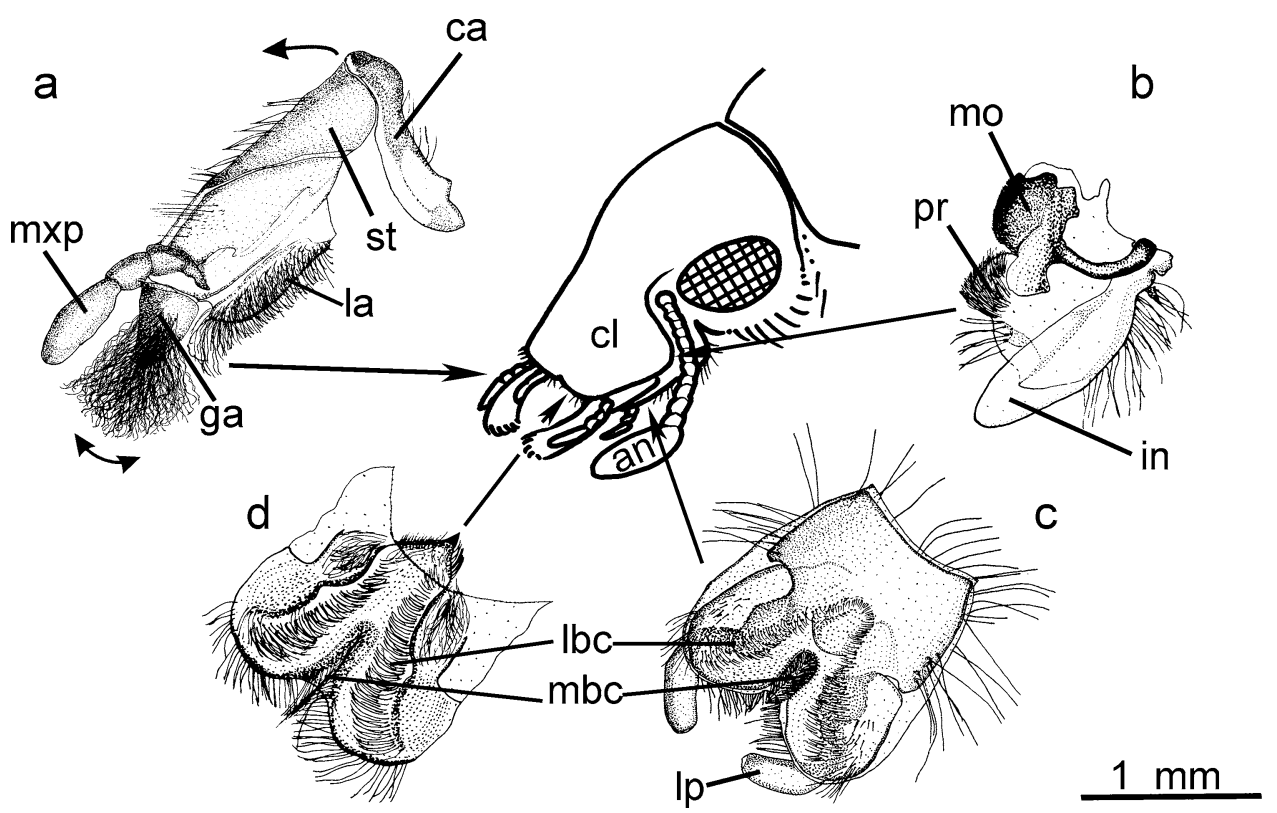

Fig. 1 Head and mouthparts of Cetonia aurata (Scarabaeidae). Straight arrows indicate position of mouthparts on the head; curved arrows indicate movements. a Maxilla swivels out laterally and extends forward; during its retraction the galea turns inward sweeping pollen to the lacinia. b Mandible with non-biting incisivus, prostheca and mola with pollen crushing surface. $\mathbf{c}$ Buccal side of labium with bristles crests. d Buccal side of labrum with bristle crests. The smooth dorsal side lies directly under the heavily sclerotised clypeus. an, antenna; ca, cardo; cl, clypeus; in, incisivus; ga, galea; la, lacinia; lbc, lateral bristle crest; lp, labial palpus; mbc, median bristle crest; mo, mola; mxp, maxillary palp; pr, prostheca; st, stipes. Bar scale applies to $\mathbf{a}-\mathbf{d}$ 
nitrogen to prevent a gaseous phase building on the surface during the shock-freezing process. After a short sublimation procedure (about $3 \mathrm{~min}$ at the temperature difference -120 and $-90^{\circ} \mathrm{C}$ ), samples were sputter-coated in the frozen condition (temperature $-140^{\circ} \mathrm{C}$, thickness $6 \mathrm{~nm}$ ) and observed in the SEM Hitachi S 4800 at accelerating voltage of $1-3 \mathrm{kV}$ and temperature of $-120^{\circ} \mathrm{C}$. The method allowed us to visualise fluids located on the cuticle surface (Gorb 2006) and to study the surface of beetle mouthparts with high resolution and with a minimum of artefacts due to treatments by solvents and drying procedure.

\section{Scanning electron microscope}

The micrographs were taken using a conventional SEM (Philips XL 20) at the Institution of Cell Imaging and Ultrastructure Research (University of Vienna, Austria).

Beetles were collected from natural food plants in surroundings of Vienna. For the SEM, the specimens were rapidly frozen on flowers of Crataegus monogyna (Rosaceae) using a Cryo Freeze Aerosol (Agar Scientific Limited), stored in a can containing a nitrogen atmosphere, put in $100 \%$ ethanol, and finally stored at $-54^{\circ} \mathrm{C}$. To dissect mouthparts under a stereo microscope, the severed heads were then embedded in a molten wax-rosin mixture using a soldering tip (Star Tec ST 081).

All specimens were dehydrated in $100 \%$ ethanol and Hexamethyldisilazan (15 min) was used as an intermedium. After air drying over night, the objects were mounted on object holders using double-sided carbon-containing adhesive tape and sputter-coated with gold $(300 \mathrm{~s}$ in an Agar sputtercoater B7340).

\section{Gut examination}

Beetles were collected from natural food plants in surroundings of Vienna and fixed in ethanol (70\%). They were dissected under a stereo microscope, and their guts were removed. Parts of fore-, and hindgut were separately mounted in Glycerine on glass slides. Digital images were taken using a light optical microscope equipped with a digital photo camera Nikon CoolPix 950.

\section{Results}

Mouthparts and feeding mechanism

In $C$. aurata, the various structures of the mouthparts function together as a pollen harvesting and processing device. The cibarial roof is formed by the clypeus and the heart shaped labrum. This rather soft structure bears two lateral bristle combs, joining proximally to a v-shaped ridge and enfolding a median crest of bristles that perches on a median keel (Fig. 1d). The lateral bristles overlie the median part of the mandibles, while the bristly epipharynx lies between the mola surfaces. In Cryo-SEM micrographs all buccal bristles of the labrum are covered with a liquid. Pollen grains were found embedded in the liquid layer situated between moist bristles of the median crest. While the thinner, inner lateral bristles of the epipharynx point in the caudal direction, the outer lateral bristle rows align towards the median keel and the median bristles reach into the preoral cavity (Fig. 2a, b).

The distal parts of the maxillae, i.e., the galeae, represent the primary organs for pollen uptake (Figs. 1a, 2d-g). The Cryo-SEM study revealed that the long bristles on the tip of the galeae are completely saturated with fluid, forming a structure that can be functionally compared with a wet brush tip taking up pollen (Fig. 2e-g). Pollen grains were also found on the lacinia bristle crests. These bristles are likewise covered with a liquid to which the grains adhere, but they do not form a brush-like structure as described for the galeal bristles (not illustrated).

Conventional SEM micrographs revealed wavy bristles at the tip of the galea and a fine serration at the tip of otherwise smooth lacinia bristles (not illustrated). These structures presumably assist the pollen transport through the cibarium. It is not expected that they support the adherence of the liquid layer to the bristle's surface otherwise the entire shaft would be serrated.

The mandibles are composed of the thin blade-like incisivus which lies alongside the basal part of the maxilla, the soft and bristly prostheca and the well developed mola region (Fig. 1b). Cryo-SEM micrographs revealed that the bristles on the inner edge of the prostheca are entirely covered with liquid and thus adhere together, forming a large and dorsally vaulted region (Fig. $2 h$ ). Due to the convex shape it was concluded that this part of the mandible works like a pollen collecting receptacle when moving inside the cibarium. These structures clearly convey pollen to the mola region. This mandibular region with a sculptured chewing surface is covered with a liquid layer. Both crushed and intact pollen grains were detected to adhere to the fluid (Fig. 2i, j). The mola are surrounded by a fringe of short multiply branched bristles and are also covered with a liquid layer (Fig. 2i). This moist fringe surrounds the mola and encompasses the chewing surface. Thus, it is interpreted as a sealing structure to prevent pollen grains from slipping off the chewing surface during the grinding process.

The strongly sclerotised labium forms the floor of the cibarium. Its buccal surface bears bristle crests similar to those on the labrum (Fig. 1c). Cryo-SEM micrographs show that the median crest of the labium is covered with a liquid filling the spaces between the distally orientated bristles. In 

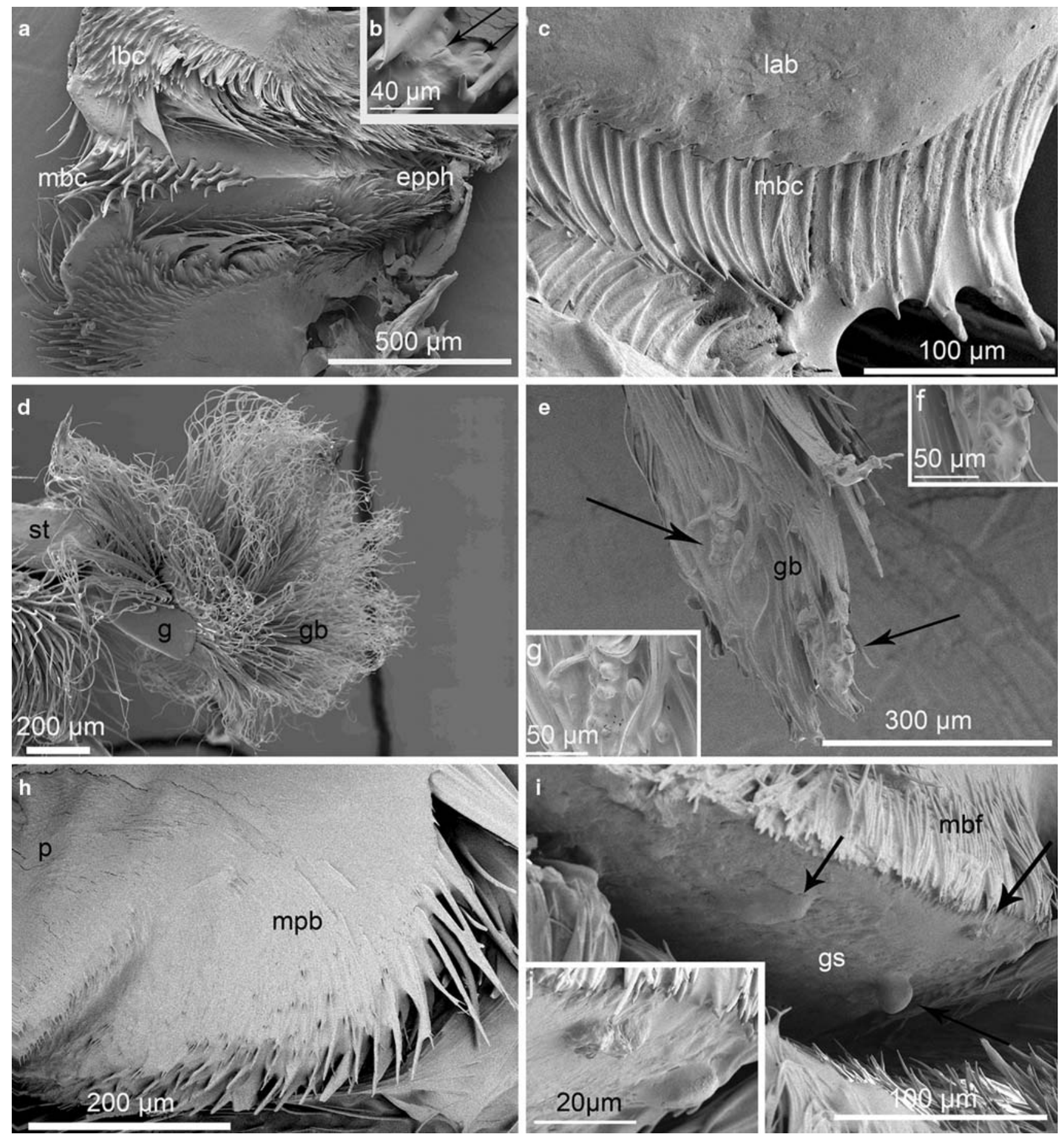

Fig. 2 Mouthparts of Cetonia aurata; Cryo-SEM micrographs (a-c, e-j) and SEM micrographs (d). a Ventral view of labrum with lateral bristle crests, median bristle crest and epipharynx. All bristles are covered with a fluid layer. b Detail of median bristle crest with pollen grains embedded in liquid layer (arrows). c Labium: dorsal view of moist median bristle crest covering the median depression. $\mathbf{d}$ Maxilla: wavy bristles of the galea forming a fan-like structure. e Galea tip, bristles forming a wet brush. Multiple pollen grains adhere to the liquid layer (arrows). f, g Pollen grains adhering to the moist galea

tip. h Mandible: prostheca bristles with liquid layer, forming a pollen trapping and transport device. i Mandible: mola with moist grinding surface and wet bristle fringe. Single pollen grains are visible (arrows). j Detail view of the mola surface with a crushed and an intact pollen grain. epph, epipharynx; g, galea; gb, galea brush; gs, grinding surface; lab, labium; lbc, lateral bristle crest; mbc, median bristle crest; mbs, moist bristle fringe; mpb, moist prostheca bristles; $\mathrm{p}$, prostheca; st, stipes 
this manner, the median depression of the labium is completely sealed off (Fig. 2c). Additionally the median bristle crest presumably serves to pass along the pollen grains.

\section{Gut content}

Numerous crushed pollen grains and a few intact ones were found in the examined gut regions (Fig. 3a, b). The anterior midgut contained about $2 \%$ of intact pollen and in the hindgut about $1 \%$ of the pollen was undamaged. In the hind gut of one specimen many pollen grains had a developed pollen tube (Fig. 3c).

\section{Discussion}

Feeding mechanism

Micrographs of the pollen feeding rose beetle, Cetonia aurata, obtained with the aid of the Cryo-SEM technique revealed that the buccal surfaces of the mouthparts were covered with a liquid coating. We conclude that this beetle uses the liquid layer to improve adhesion of pollen grains to the mouthparts. In particular, the long wavy bristles which form the galeal brushes most likely aid in retaining the fluid at the galeal tip. The moistened galeal brushes serve as effective pollen removal devices. Pollen is removed from the anthers probably not by the sweeping motion of the galeal tips, as proposed by Bürgis (1986a, b), rather by daubing the anthers with the moistened galeal brushes. This conclusion is based on the observation that the brushes and cuticle of the shock frozen mouthparts showed evidence of wetness, however this has not been experimentally verified.

The origin of the liquid is uncertain since salivary glands are allegedly absent in most Coleoptera (Beutel 2003) and are only known in representatives of few families in Coleoptera, such as Rhysodidae and Coccinellidae (Beutel 2003). However, the observed lubrication of the mouthparts could have been produced by the mandibular glands which are present in Coleoptera (Chapman 1998).
Data on head glands in representatives of Cetoniinae are absent in the literature. The buccal liquid is possibly of extracorporeal origin. It may consist of nectar regurgitated from the foregut. Other specialised flower visiting insects like Apis mellifera regurgitate nectar to enhance the stickiness of pollen kit (Hesse 1980). This substance plays an important role in the adherence of pollen grains to each other and to the pollen collecting structures of bees.

The mouthparts of $C$. aurata have completely lost toothlike structures that in other species of the subfamily Cetoniinae occur on the distal parts of mandible (Fuchs 1974) and maxilla (Bürgis 1989). While the maxillae primarily represent the pollen uptake organs, the mandibles serve two functions. First, the prostheca functions as a pollen conveying structure by sweeping the pollen between the mola surfaces. This hypothesis is supported by the fact that scattered pollen grains are visible in the SEM micrographs of this region. Second, the mandibles grind pollen; the molar parts work as a pollen mill, crushing pollen grains before they are swallowed. The moist fringe prevents pollen from slipping off the grinding surface. Both labrum and labium with their rows of moistened lateral bristles operate together to seal the oral cavity. Additionally, the moistened vertically orientated median crests and probably also the lateral bristle rows further convey pollen.

\section{Mouthparts in flower visiting beetles}

Representatives of protea beetle (Cetoniini) and monkey beetles (Hopliini) are reputed to be the pollinators for several South African plants (Johnson and Nicolson 2000). Their mouthparts are similar to $C$. aurata, i.e., equipped with numerous rows of bristles and the dense galeal brushes. The mandibles and maxillae are smooth plates lacking cutting edges and exhibit a similar semicircular movement when taking food from flowers. Furthermore, these beetles are able to take up liquids by licking motions of the galeal brushes. The liquid is then presumably squeezed out when the labrum and labium are pressed together (Johnson and Nicolson 2000). C. aurata is also recorded to ingest nectar, plant saps and
Fig. 3 C. aurata: Lightmicroscopical micrographs of the pollen grains in the gut. a Intact and crushed pollen grains from foregut in detail. $\mathbf{b}$ Numerous crushed and single intact pollen grains in the foregut. c Pollen grains with pollen tubes
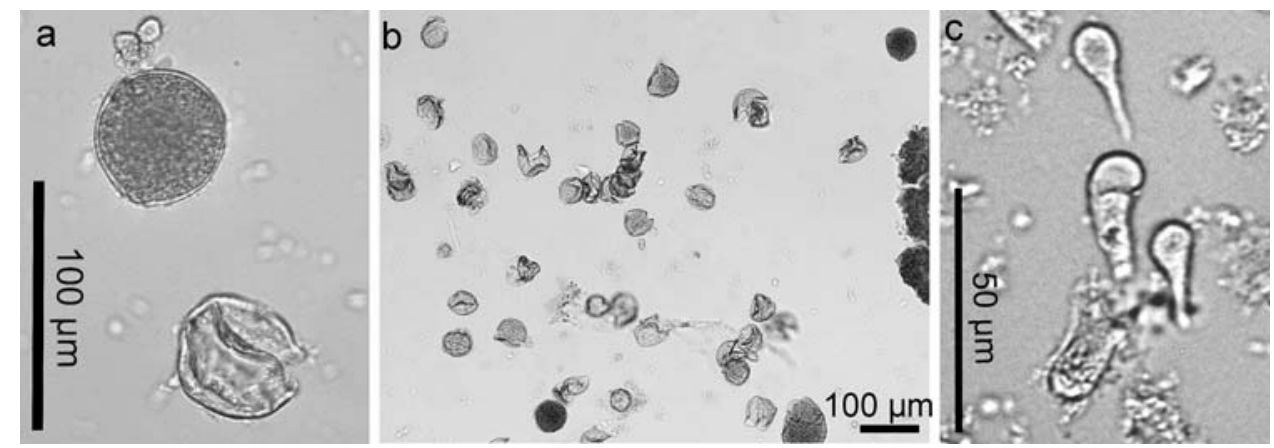
liquids from rotten fruits (Bürgis 1989). Based on the morphological similarity of its mouthparts to protea beetles and monkey beetles, it can be assumed that the mouthparts work in a comparable way to imbibe liquids. Whether these flower visiting Coleoptera also employ a buccal fluid when feeding on pollen is not known.

In pollen feeding beetles variously shaped galea bristles were described (Fuchs 1974). For example a knob-like relief or a corrugate surface are well suited to engage structured pollen grains and enhance the ability of pollen attachment. In Addition branched bristles and enlarged surfaces help convoy pollen towards the mandibles (Fig. 4). The galea bristles of $C$. aurata however are only undulate but function as adhesion structures in conjunction with fluid.

Beetles continue to be rather poorly studied as flower visitors compared to Hymenoptera and Lepidoptera (Krenn et al. 2005). As a result they are rarely considered to be specialised flower visitors or pollinators. The opinion is common that they do more harm to the flowers than benefit to the plant. This does not apply to $C$. aurata since its mouthparts lack cutting edges which could damage vital parts of flowers. Furthermore, species of the related Hopliini, are important pollinators of plants from families Asteraceae and Mesembryanthemaceae in South Africa (Picker and Midgley 1996). We expect that there is a wide repertoire of mouthpart adaptations to floral feeding in beetles which serve as a pollinating vector.

One of the well-investigated example of a pollen feeding beetle is Malachius bipustulatus (Malachiidae). Although its maxillae have special bristles for pollen uptake, they function differently from those in C. aurata. While the galeal surface is covered with numerous trumpet shaped bristles, the lacinia has spoon shaped bristles (Fig. 4b) which are also found laterally on the labium. Pollen grains adhere to slightly concave tips of the trumpet shaped setae and, during the retraction of the maxillae, the spoon shaped bristles of the labium sweep away the pollen. Finally, sweeping movements of the laciniae convey the pollen grains to the mandibles where they are crushed. The prostheca prevents pollen grains from escaping the cibarium and works as a guiding structure for the powdery meal (Schicha 1967). Apparently, M. bipustulatus relies on the specialised configuration of bristle tips instead of the rough surface or the liquid layer to convey pollen through the cibarium. Similar configurations have convergently evolved on the ventral surfaces of the tarsal pads of Coleoptera and Diptera specialised for adhesion to flat surfaces (Bauchhenss 1979; Stork 1980; Gorb 2001).

Pollen and spore feeding behaviour of Staphylinoidea was studied in detail by Betz et al. (2003). Sporophagy is a common feeding preference with particular demands on mouthpart morphology that are functionally similar to those of pollen feeding. Special adaptations for both kinds of particle feeding include brush, rake or comb like structures on the maxillae for sweeping particles, as well as setose structures on the mandible for further conveyance of the food. The mola is often reinforced with grinding structures, and the prostheca shows a microstructural diversification for sweeping particulate food material off the maxillae. The cibarial roof, epi- and hypopharynx show various microtrichia and bristle-troughs, for guiding the food through the cibarium (Betz et al. 2003).
Fig. 4 Various types of specialised maxilla bristles of pollen feeding beetles. a Branched bristles. b Trumpet and spoon shaped bristles of Malachius bipustulatus (Malachiidae). c Adhesion surfaces with sculptured cuticle. d Variously broadened tips without sculptured surfaces. e Wavy bristles and serrated bristles covered with fluid in Cetonia aurata (Scarabaeidae). ga, galea; la, lacinia (modified after Schicha 1967 and Fuchs 1974)

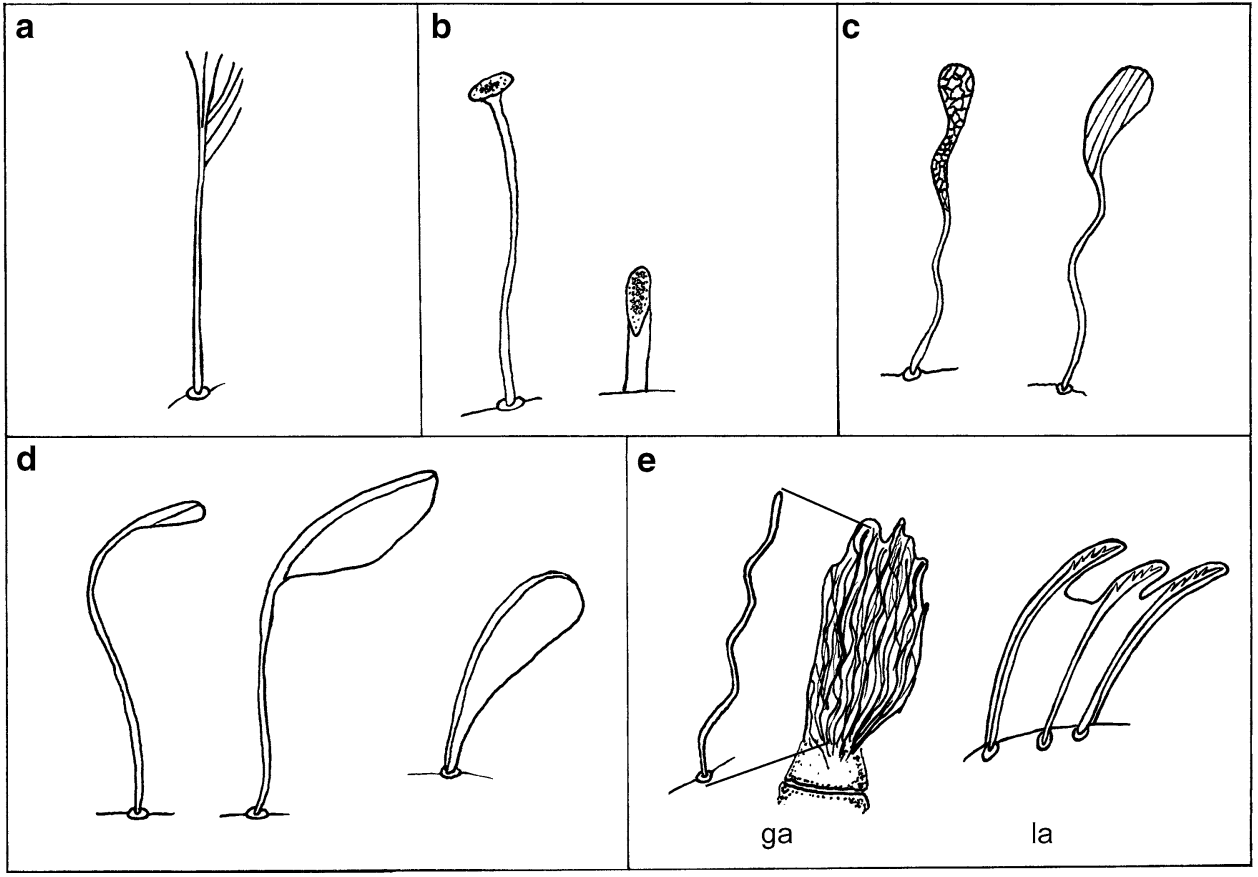


Pollen digestion

Various mechanisms of pollen digestion have evolved in Coleoptera. Our study of $C$. aurata revealed that the mola of the mandibles are able to crush pollen grains. This is supported by observations of crushed pollen grains on the mola in Cryo-SEM preparations and the fact that crushed pollen grains are detectable in all gut sections. Thus the pollen is mechanically opened by action of the mandibles. Osmotic damaging of pollen occurs in the guts of South African protea beetles and monkey beetles whereby the pollen wall is weakened enabling digestive enzymes to enter via the pores (Johnson and Nicolson 2000). Since a small portion of undamaged pollen grains was found in all gut regions of $C$. aurata, we conclude that no further chemical process was necessary to destroy pollen exine in the digestive tract.

Another technique of pollen destruction was described in the pollen feeding beetle Cyclocephala amazona (Scarabaeidae) which ingests multicellular trichomes from the inflorescence axis of Bactris gasipaes, the beach palm of Central America, before consuming pollen. The thick walled and lignified trichomes offer no nutritional value, but work as gastroliths to crush the strong pollen walls in the beetle's gut (Rickson et al. 1990).

Pollen grains in which a pollen tube has developed were found in the hindgut of one specimen of $C$. aurata. It is reported that nectar in the gut of some insects, such as certain hoverflies (Haslett 1983) and bees (Peng et al. 1985; Dobson and Peng 1997), can initiate pseudo-germination of pollen grains. The initiation of short pollen tubes is followed by an exudation of digestible protoplasmic content from germination pores in the wall (Johnson and Nicolson 2000). However we assume that a certain amount of pollen grains have already begun to germinate before uptake.

\section{Cryo-SEM methods}

Many surface functions rely on the combination of microstructure and fluids. Therefore direct detailed visualisation of the fluid-solid surface interaction at high resolution may provide new insights into working principles of biological functional systems. The Cryo-SEM method has been previously applied for visualisation footprints of flies Calliphora vicina (Gorb 2006) and beetles Gastrophysa viridula (Schuppert and Gorb 2006), epicuticular grease on the elytra of the beetle Leptinotarsa decemlineata (Voigt et al. 2008) and water droplets on various surfaces of carnivore plants (Gorb et al. 2007).

The Cryo-SEM approach yields not only qualitative but also quantitative information. Of course, as every microscopy method, the Cryo-SEM approach is not absolutely free of artefacts. Typical Cryo-SEM artefacts are contamination of the surface by ice crystals, foaming of the fluid mixtures during freezing, partial sublimation of water from mixtures. Some of these can be avoided by short sublimation of the sample in the preparation chamber and more rapid freezing procedure by the use of liquid nitrogen at its melting point in vacuum. Thus, the Cryo-SEM method must be applied in combination with other microscopy techniques, including conventional SEM, phase contrast light microscopy and various preparation techniques. The application of new microscopic and experimental methods is essential for a deeper understanding of such pollen feeding insects. We have demonstrated here that the combination of Cryo-SEM and conventional SEM procedures is a promising approach to obtain detailed information about mouthparts in fresh and dried conditions and to draw conclusions on the feeding mechanisms of flower visiting insects.

Acknowledgements The authors would like to thank Dr. W. Klepal and D. Gruber from the Institution of Cell Imaging and Ultrastructure Research at the University of Vienna for providing access to the SEM-unit and for their assistance in scanning electron microscopy. We also want to thank John Plant for providing assistance with the English text, as well as the two anonymous reviewers who helped to improve the manuscript. This work, as part of the European Science Foundation EUROCORES Programme FANAS was supported from funds by the German Science Foundation DFG (contract No GO 995/ 4-1) and the EC Sixt Framework Programme (contract No ERAS-CT2003-980409) to S.N.G.

\section{References}

Bauchhenss E (1979) Die Pulvillen von Calliphora erythrocephala Meig. (Diptera, Brachycera) als Adhäsionsorgane. Zoomorphology 93:99-123. doi:10.1007/BF00994125

Betz O, Thayer TK, Newton AF (2003) Comparative morphology and evolutionary pathways of the mouthparts in spore-feeding Staphylinoidea (Coleoptera). Acta Zool 84:179-238. doi: 10.1046/j.1463-6395.2003.00147.x

Beutel RG (2003) 26. Ordnung Coleoptera, Käfer. In: Dathe HH (Hrsg.) Lehrbuch der speziellen Zoologie begründet von Alfred Kaestner Band I: Wirbellose Tiere 5. Teil: Insecta, 2. Aufl. Spektrum Akademischer Verlag, Heidelberg, Berlin, pp 426-526

Bürgis H (1986a) Blütenfressende Blatthornkäfer (Anthophaga), Der Rosenkäfer Cetonia aurata und seine Verwandten. 1. Kopf und Mundwerkzeuge. Mikrokosmos 75(7):207-211

Bürgis H (1986b) Blütenfressende Blatthornkäfer (Anthophaga), Der Rosenkäfer Cetonia aurata und seine Verwandten. 2. Das Zusammenspiel der Mundwerkzeuge. Mikrokosmos 75(11): $327-330$

Bürgis H (1987) Blütenfressende Blatthornkäfer (Anthophaga), Der Rosenkäfer Cetonia aurata und seine Verwandten. 3. Der Kaubezirk. Mikrokosmos 76(12):346-366

Bürgis H (1989) Blütenfressende Blatthornkäfer (Anthophaga), Der Rosenkäfer Cetonia aurata und seine Verwandten. 4. Die Nahrung des Rosenkäfers Cetonia. Mikrokosmos 78(2):50-53

Chapman RE (1998) The insects. Structure and function, 4th edn. Cambridge University Press, Cambridge 
Dobson HEM, Peng Y (1997) Digestion of pollen components by larvae of the flower-specialist bee Chelostoma florisomne (Hymenoptera: Megachilidae). J Insect Physiol 43:89-100. doi: 10.1016/S0022-1910(96)00024-8

Fuchs GV (1974) Die Gewinnung von Pollen und Nektar bei Käfern. Nat Mus 104:45-54

Gorb SN (2001) Attachment devices of insect Cuticle. Kluwer Academic Publishers, Dordrecht

Gorb SN (2006) Fly microdroplets viewed big: a Cryo-SEM approach. Microsc Today September 2006:38-39

Gorb SN, Voigt D, Gorb EV (2007) Visualisation of small fluid droplets on biological and artificial surfaces using the Cryo-SEM approach. In: Méndez-Vilas A, Díaz J (eds) Modern research and educational topics in microscopy, vol 2. Formatex, Badajoz, pp 812-819

Haslett JR (1983) A photographic account of pollen digestion by adult hoverflies. Physiol Entomol 8:167-171. doi:10.1111/j.13653032.1983.tb00345.x

Hesse M (1980) Zur Frage der Anheftung des Pollens an blütenbesuchende Insekten mittels Pollenkitt und Viscinfäden. Plant Syst Evol Suppl 133:135-148

Johnson SA, Nicolson SW (2000) Pollen digestion by flower-feeding Scarabaeidae: protea beetles (Cetoniini) and monkey beetles (Hopliini). J Insect Physiol 47:725-733. doi:10.1016/S00221910(00)00166-9

Krenn HW, Plant JD, Szucsich NU (2005) Mouthparts of flowervisiting insects. Arthropod Struct Dev 34:1-40. doi:10.1016/ j.asd.2004.10.002

Nel A, Scholtz CH (1990) Comparative morphology of the mouthparts of Scarabaedoidea (Coleoptera). Entomol Mem 80:1-84
Peng Y, Nars ME, Marston JM, Fang Y (1985) The digestion of dandelion pollen by adult worker honeybees. Physiol Entomol 10:75-82. doi:10.1111/j.1365-3032.1985.tb00021.x

Picker MD, Midgley JJ (1996) Pollination by monkey beetles (Coleoptera: Scarabaeidae: Hopliini): flower and colour preferences. Afr Entomol 4:7-14

Rickson FR, Cresti M, Beach JH (1990) Plant cells which aid in pollen digestion within a beetle's gut. Oecologia 82:424-426. doi:10.1007/BF00317493

Schicha E (1967) Morphologie und Funktion der Malachiidenmundwerkzeuge unter besonderer Berücksichtigung von Malachius bipustulatus L. (Coleopt., Malacodermata). Z Morphol Oekol Tiere 60:376-433. doi:10.1007/BF00424639

Schremmer F (1961) Morphologische Anpassung von Tiereninsbesondere Insekten-an die Gewinnung von Blumennahrung. Verh Dtsch Zool Ges (Zool Anz, Suppl) 25:375-401

Schuppert J, Gorb S (2006) The wet step: visualisation of the liquid bridges in the attachment pads of the beetle Gastrophysa viridula. Society for Experimental Biology Main Meeting, University of Kent, Canterbury, 2-7 April 2006. Comp Biochem Physiol A 143(Suppl 1):Abstract No. A7.23

Stanley RG, Linskens HF (1974) Pollen: biology biochemistry management, vol VI. Springer Verlag, Heidelberg, p 307

Stork NE (1980) A scanning electron microscope study of tarsal adhesive setae in the Coleoptera. Zool J Linn Soc 68:173-306. doi:10.1111/j.1096-3642.1980.tb01121.x

Voigt D, Schuppert JM, Dattinger S, Gorb SN (2008) Sexual dimorphism in the attachment ability of the Colorado potato beetle Leptinotarsa decemlineata (Coleoptera: Chrysomelidae) to rough substrates. J Insect Physiol. doi:10.1016/j.jinsphys.2008.02.006 